\title{
A ECONOMIA POLÍTICA DOS ESTADOS UNIDOS E DA CHINA PÓS CRISE DE 2008: INTERDEPENDÊNCIA ECONÔMICA E RELAÇÕES INTERESTATAIS
}

\author{
Valéria Lopes Ribeiro ${ }^{1}$
}

\begin{abstract}
Resumo: O artigo tem como objetivo analisar o padrão de crescimento dos Estados Unidos e da China no período posterior a crise de 2008 e as interconexões entre os dois países em termos de comércio, fluxos financeiros e investimentos. A pesquisa parte das contribuições teóricas de autores recentes no campo da Economia Política Internacional: Leo Panitch e Alex Callinicos em seus trabalhos relacionados ao tema da posição dos Estados Unidos no mundo. A partir desta discussão o artigo identifica através de uma análise empírica as características da economia dos EUA e da economia chinesa, bem como a interdependência entre elas. Dentro deste escopo o artigo discute ainda os impactos destas mudanças nas relações interestatais entre China e EUA e as consequências para os demais países.
\end{abstract}

Palavras-Chave: Estados Unidos; China; Economia Política; Relações interestatais

\section{THE POLITICAL ECONOMY OF THE UNITED STATES AND CHINA AFTER THE 2008 CRISIS: ECONOMIC INTERDEPENDENCE AND INTER-STATE RELATIONS}

\begin{abstract}
The paper aims to analyze the growth pattern of the United States and China in the post - 2008 crisis period and the interconnections between the two countries in terms of trade, financial flows and investments. The research is based on the theoretical contributions of recent authors in the field of International Political Economy: Leo Panitch and Alex Callinicos in their work related to the theme of the United States' position in the world. From this discussion the article identifies through empirical analysis the characteristics of the US economy and the Chinese economy, as well as the interdependence between them. Within this scope the article also discusses the impacts of these changes in inter-state relations between China and the USA and the consequences for the other countries

Keywords: United States; China; Political economy; Interstate relations

\section{LA ECONOMÍA POLÍTICA DE ESTADOS UNIDOS Y CHINA DESPUÉS DE LA CRISIS DE 2008: INTERDEPENDENCIA ECONÓMICA Y RELACIONES INTERESTATALES}

Resumen: El artículo tiene como objetivo analizar el patrón de crecimiento de Estados Unidos y China en el período posterior a la crisis de 2008 y las interconexiones entre los dos países en términos de comercio, flujos financieros e inversiones. La investigación parte de las contribuciones teóricas de autores recientes en el campo de la Economía Política Internacional: Leo Panich y Alex Callinicos en sus trabajos relacionados con el tema de la posición de Estados Unidos en el mundo. A partir de esta discusión el artículo identifica a través de un análisis empírica las características de la economía de EEUU y de la economía china, así como la interdependencia entre ellas. Dentro de este ámbito el artículo discute aún

\footnotetext{
1 Doutora em Economia Política Internacional pelo Programa de Pós-Graduação em Economia Política Internacional da Universidade Federal do Rio de Janeiro (UFRJ). Professora Adjunta de Relações Internacionais da Universidade Federal do ABC (UFABC). Email: valrib2015@gmail.com
} 
los impactos de estos cambios en las relaciones interestatales entre China y EEUU y las consecuencias para los demás países.

Palabras clave: Estados Unidos; China; Economía Política; Relaciones interestatales

\section{1 - Introdução}

Dez anos após a crise de 2008 a economia mundial ainda não conseguiu recuperar grandes patamares de crescimento. Mesmo nas economias avançadas observa-se um quadro de baixo crescimento acompanhado do aumento das desigualdades sociais e econômicas, além da continuidade da adoção de medidas de austeridade como a única resposta aos crescentes déficits governamentais. (UNCTAD, 2017²).

Com a crise financeira de 2008 originada em Wall Street ${ }^{3}$ o modelo neoliberal fundado na expansão e globalização financeira demonstrou de maneira ainda mais evidente suas inconsistências, principalmente em promover melhores condições de renda e riqueza para a grande maioria das populações. A crise veio, nesse sentido, expor ainda mais as contradições do modelo e a contradição fundante das crises no capitalismo, qual seja, a socialização da produção - agora a nível global - contraposta à apropriação privada do valor gerado, cada vez mais concentrado nas mãos de poucos. (MARX, 1984).

A crise e a consequente dificuldade dos países em retomar os níveis de crescimento anteriores instaura cada vez mais dentro das próprias economias avançadas algumas manifestações da contradição fundante, como, por exemplo, a dificuldade em expandir níveis de emprego, salário e renda aos mais pobres. E mesmo diante do baixo nível de crescimento os governos não parecem dispostos a promover medidas de recuperação de maior dimensão, como a regulamentação do sistema financeiro ou medidas mais anticíclicas, insistindo apenas na saída pela austeridade que leva à precarização ainda mais acentuada das condições de vida das camadas médias e mais pobres, mesmo nas economias centrais. (UNCTAD, 2017).

O cenário da economia global pós crise de 2008 é também marcado pela continuidade da importância das duas maiores economias mundiais, os Estados Unidos e a China, que juntas continuam respondendo por parcela significativa do PIB mundial.

\footnotetext{
${ }^{2}$ UNCTAD (2017). "Trade and Development Report 2017: Beyond Austerity: towards a global new deal"

${ }^{3} \mathrm{O}$ objetivo do artigo não é explicar as causas da crise, mas sim suas consequências. O tema das causas da crise pode ser encontrado, por exemplo, em Duménil e Lévy (2014).
} 
Mesmo enfrentando dificuldades relacionadas à expansão dos níveis de renda internos a economia americana segue como a maior economia mundial, crescendo a taxas menores, mas expandindo a produtividade do trabalho e atraindo Investimentos Diretos de todo o mundo. O dólar segue mantendo sua posição de moeda global, tendo a crise marcado inclusive a crescente fuga dos capitais para o próprio dólar. (PANITCH e GINDIN, 2013).

Ainda assim, a crise e as consequências para a economia real americana instauram um ambiente onde até mesmo teóricos de orientação liberal como Ikenberry (2017), demonstram a percepção de que os Estados Unidos estariam aos poucos perdendo sua posição de liderança global, tanto pelas contradições de sua economia como pela manifestação destas contradições na política interna americana.

O fenômeno Trump é certamente um importante fator nesse debate, tendo contribuído para instaurar um ambiente político e intelectual americano de bastante pessimismo com relação ao futuro dos Estados Unidos como líder global.

Do outro lado do mundo, após quase quatro décadas de crescimento econômico ininterrupto, a crise de 2008 parece não ter colocado em cheque a longa trajetória de ascensão da China, que já é considerada a segunda maior economia do mundo (ou até a primeira em termos de paridade de poder de compra).

Apresentando-se cada vez mais como uma economia moderna, fortemente baseada na indústria e no setor de serviços e avançando nos estágios mais avançados das cadeias de valor globais, a China sentiu as os efeitos adversos da crise principalmente por meio de uma queda na demanda global por suas exportações. O país enfrentou os desafios por meio de uma forte alavancagem financeira e, em seguida, a sinalização de entrada do país em um novo ciclo de crescimento baseado em taxas mais baixas de crescimento do PIB e expansão do consumo, o chamado New Normal.

Estados Unidos e China seguem assumindo uma posição central na dinâmica econômica global e em meio ao cenário de menor crescimento pós crise mantém um forte grau de interconexão de suas economias, que remete aos anos 70, período em que a retomada da hegemonia americana sustentou-se em uma reviravolta da política monetária que resultou na instauração do ambiente monetário internacional propício tanto à expansão da financeirização como, ao mesmo tempo, à fragmentação da produção manufatureira mundial com a expansão dos Investimentos Diretos para a Ásia. (TAVARES, 1985). 
Desde essas transformações instaurou-se o que se poderia denominar de nova divisão internacional do trabalho, marcada pela ascensão da produção industrial asiática e principalmente chinesa, permanecendo nas economias centrais nichos das cadeias globais de maior valor agregado e o controle dos mercados de capitais.

Inserindo-se nessa dinâmica global a China seguiu sua longa trajetória de expansão econômica fundada em um padrão de crescimento industrial sustentado pelo Estado que promoveu grandes transformações no país.

Aproveitando-se do aumento de suas exportações para todo o mundo a partir dos anos 80 e 90 (e para os EUA em particular) e ampliando o Investimento estatal (variável chave na explicação da expansão do PIB chinês) a China retirou quase 400 milhões de pessoas da pobreza (em 5 anos entre 1980 e 1985) e em cerca de 30 anos mudou completamente a estrutura econômica do país, com a indústria e o setor de serviços respondendo por mais de $70 \%$ do PIB. Essa mudança estrutural retirou milhões de pessoas do campo promovendo o maior processo de migração e urbanização já visto na história. Um processo de crescimento com industrialização e incorporação da mão de obra que transformou e vem transformando completamente uma sociedade milenar que já conta com quase 1,4 bilhões de pessoas.

Talvez tão surpreende quanto o fenômeno chinês recente em si seja o fato de que ele ocorre justamente dentro de uma ordem mundial ainda amplamente dominada e sustentada pela economia americana, o que faz com que em muitos sentidos o crescimento chinês não possa ser entendido fora dessa ordem, estando sua economia ligada até hoje - ao menos até a crise de 2008 - à economia americana.

A forte inter-relação entre as duas economias fez com que em meados de 2006 Neil Ferguson cunhasse o termo "Chimerica" para o que denominou ser a relação simbiótica entre China e Estados Unidos. Muito mais que dois países com intrincadas relações financeiras e comerciais, seria segundo o autor, uma relação simbiótica que teria contribuído para o contexto de prosperidade e criação de riqueza que marcou o período pré-crise de $2008 .{ }^{4}$

\footnotetext{
${ }^{4}$ Em 2007 Ferguson escreve no Telegraph “ Think of the United States and the People's Republic not as twocountries, but as one: Chimerica. It's quite a place: just 13 per cent of the world's land surface, but a quarter of its population and fully a third of its economic output. What's more, Chimerica has accounted for around 60 per cent of global growth in the past five years. Their relationship isn't necessarily unbalanced; more like symbiotic. East Chimericans are savers; West Chimericans are spenders. East Chimericans do manufactures; West Chimericans do services. East Chimericans export; West Chimericans import. East Chimericans pile up reserves; West Chimericans obligingly run deficits, producing the dollar-denominated bonds that the East Chimericans crave. As in all good marriages, the differences between the two halves of Chimerica are complementary. Disponível em http://www.telegraph.co.uk/comment/personal-view/3638174/Not-twocountries-but-one-Chimerica.html. Já em 2009, sob efeitos da crise de 2008, Ferguson escreveria outro artigo,
} 
Apesar da forte interdependência e da ascensão chinesa, Panitch e Gindin (2013) argumentam que, mesmo com a entrada da China e da relação simbiótica entre os dois países, os EUA continuam a assumir papel central no capitalismo internacional, ainda que novos elementos tenham surgido em torno e relacionados a essa centralidade.

Os novos elementos que reconfiguram - mas não abalam - a centralidade americana seriam, por exemplo, o que os autores chamam de um alargamento da manufatura, uma espécie de nova hierarquia de produção global em que o mundo em desenvolvimento inserese de forma importante assumindo a produção de artigos industrializados, enquanto o mundo desenvolvido dedica-se a pesquisa e desenvolvimento, design e marketing. Nesse contexto a Ásia e a China são centrais na medida em que se inserem nessa nova hierarquia de forma bem sucedida. (PANITCH E GINDIN, 2013).

Apesar dessa inserção, segundo os autores, tanto a Ásia como a China ainda crescem de forma muito dependente do mercado global e dos EUA e a entrada da China representa nesse sentido a aceitação das regras da OMC, a abertura de seus mercados para empresas estrangeiras e a garantia das remessas de lucros para os EUA. (Panitch e Gindin, 2013).

Outro elemento que reposiciona a centralidade da economia americana seria a aceleração da globalização financeira. Apresenta-se nesse aspecto uma divisão a partir da qual o Norte controla e centraliza os lucros das corporações, principalmente americanas, e os fluxos de capitais dos países em desenvolvimento que migram para os EUA, principalmente as reservas de países em desenvolvimento. Ressaltando-se que as empresas financeiras permanecem sendo em sua maioria americanas.

A crise de 2008, segundo os autores, reforça o papel dos EUA. A causa dessa crise não seria a fragilidade externa americana frente a outros países (o déficit com a China, por exemplo), mas sim contradições domésticas ligadas a enorme financeirização das hipotecas e a expansão do crédito ao consumo. A injeção de crédito estimulou o consumo nos EUA e eliminou as limitações que de outro modo surgiriam em contexto de grande déficit comercial. Todos foram atingidos pela crise, mas quando tiveram que buscar soluções voltaram-se para os EUA. O resultado foi o fortalecimento do dólar, com todos fugindo para ações, ativos e

intitulado "The end of chimerica". Segundo o autor a crise de 2008 teria de certa forma colocado em cheque, ou ao menos tensionado a relação simbiótica entre China e Estados Unidos e seus papéis de poupadores e compradores. A crise dos mercados imobiliários americanos impactou fortemente a capacidade de crédito e fluxo de capitais no mundo todo, repercutindo negativamente na capacidade de recuperação das taxas de crescimento não apenas nos EUA, mas em quase todos os países do mundo. 
para a dívida pública americana. O déficit americano não seria nesse sentido um problema em si, primeiro porque não está relacionado à queda nas exportações, mas ao aumento nas importações (mais consumo indicaria assim a manutenção da centralidade dos EUA) e segundo porque as inversões de capital e financeira continuam migrando para lá 5 .

Partindo de uma perspectiva distinta, Callinicos (2005;2015) questiona a ideia da crença no poder unilateral americano. Para o autor esta crença estaria enfrentando recentemente sérios problemas, tanto teóricos como políticos. Em seu texto do 2015 o autor afirma que no período pós crise de 2008 a China e outras economias emergentes recuperaramse muito mais rapidamente. Teria sido precisamente durante a crise que a China emergiu como a segunda maior economia no mundo e também como a principal produtora, exportadora e consumidora de energia. (Callinicos, 2014).

A partir de uma visão distinta com relação a Panitch e Gindin, Callinicos afirma que a conjuntura global pós crise marcaria mudanças importantes ligadas as dificuldades enfrentadas pela economia americana. $\mathrm{O}$ argumento do autor caminha para a visão de que as transformações observadas ao longo das últimas décadas e depois da crise de 2008 demonstram que a redistribuição global do poder econômico está conduzindo a uma intensificação da concorrência geopolítica, inclusive mediante a entrada da China e não necessariamente a afirmação do poder global americano, que passa a enfrentar diversas crises, entre elas a ascensão chinesa. (Callinicos, 2014)

$\mathrm{Na}$ tentativa de contribuir nesse debate, principalmente nos termos da abordagem de Panitch e Gindin (2013) o objetivo do artigo é analisar o padrão de crescimento das economias americana e chinesa nos dez anos após a crise de 2008. A ideia é investigar os motores da expansão destas duas economias ao longo destes anos e os impactos destas mudanças para as relações entre elas e suas posições no cenário global. De certa forma pretende-se responder a algumas questões que surgem principalmente a partir da argumentação de Panitch e Gindin, quais sejam: Houve uma mudança do padrão de crescimento americano no período pós-crise? Quais as contradições desse padrão em termos de geração de renda e emprego? Quais as atuais conexões entre a economia americana e a

\footnotetext{
${ }^{5}$ Ainda na Introdução de seu livro, Panitch e Gindin discorrem sobre as consequências da crise, apontando que ainda estaria por serem verificados os impactos dessa crise. Ainda assim, para os autores, seria possível observar que resulta da crise um compromisso por parte dos países em seguir adiante na manutenção da globalização, evitar o protecionismo e ampliar a cooperação com os Estados Unidos na busca por conter a crise.
} 
chinesa? Estariam os chineses em uma clara tentativa de romper com a dependência dos EUA com relação ao mercado consumidor e a direção dos fluxos financeiros?

O artigo está organizado da seguinte forma: além desta Introdução a seção 2 analisa o padrão de crescimento recente americano e chinês; a seção 3 discute a inter-relação entre as duas economias; a seção 4 apresenta os impactos dessas mudanças para as relações interestatais; a seção 5 apresenta as conclusões.

\section{2 - O padrão de crescimento dos Estados Unidos e da China pós 2008}

A capacidade dos EUA em manter um crescimento tão sustentado ao longo dos anos sustentou-se no convívio com crescentes desequilíbrios externos, traduzidos em déficits comerciais persistentes. O déficit americano começa a aumentar no começo dos 80 , reduz-se na virada dos 90 e depois cresce continuamente. Na segunda metade dos 80 os EUA tornamse devedores externos líquidos e são hoje os maiores devedores externos líquidos do mundo em termo absolutos.

Como se sabe as raízes deste aparente paradoxo devem ser buscadas nas mudanças que ocorreram na economia mundial ainda nos anos 60 e, principalmente, na resposta orquestrada pela política monetária norte-americana a essas mudanças, já na década de 70 . A manutenção da supremacia, mesmo diante de crescentes déficits deve-se, em boa medida, a forma como o país enfrentou as transformações ocorridas naquele período, no bojo do rompimento do chamado acordo de Bretton Woods. Desde esse período e do fim da conversibilidade do dólar, a moeda americana se transforma em meio de pagamento e de reservas internacional. A economia americana é sustentada na força desse arranjo monetário (aliada a força bélica do país) que permite que os déficits comerciais não encontrem limites, dada a continuidade da inversão de capital interno para o país, na forma de compra de títulos e bônus de dívida, remessas de lucro ou investimentos diretos externos. O arranjo permitiu a manutenção de taxas de crescimento e expansão da renda interna ao longo dos anos 80 e 90. (TAVARES; BRAGA e CINTRA, 2004).

Algumas décadas depois, no período posterior a crise de 2008, a economia americana passa a crescer a um ritmo inferior e a enfrentar algumas dificuldades, principalmente do ponto de vista distributivo. O período coincidiu com os dois governos de Barack Obama (2009-2016) e a entrada de Donald Trump em 2017. Coube então a Obama a responsabilidade 
de enfrentar as consequências da crise cujas causas encontram-se muito além de seu próprio governo, ou mesmo em seu antecessor, George W. Bush.

De fato, a economia americana já desde os primeiro anos do século XXI não crescia a taxas muito elevadas (entre 1991 e 2000 a média de crescimento foi de 3,6\% ao ano). Entre 2001 e 2008 os EUA cresceram a 2,5\% ao ano, ritmo baixo comparado ao ritmo de crescimento das economias em desenvolvimento, que cresceram $6,2 \%$ no mesmo período, puxados principalmente pela China $(10,9 \%)$ mas também pela África $(5,7 \%)$ Índia $(7,6 \%)$ e Rússia (6,8\%). (UNCTAD, 2017)

Ainda assim ao longo da primeira década do século XXI a economia americana seguiu mantendo sua posição de maior economia mundial, mas com relação ao período pós crise algumas mudanças apresentam-se. A Tabela abaixo mostra dados sobre o crescimento americano de 2000 a 2016.

Tabela 1 - Estados Unidos: Indicadores (2000-2008/2008-2016)

\begin{tabular}{|l|r|r|r|r|r|}
\hline & $\%$ PIB & & $\%$ PIB crescimento anual \\
\hline Despesa de consumo final das famílias & 2000 & 2008 & 2016 & $2000-2008$ & $2008-2016$ \\
\hline Despesa de consumo final do governo & 66,04312 & 68,03402 & 68,83788 & 2,87 & 1,59 \\
\hline Formação Bruta de Capital Fixo & 14,04185 & 16,09235 & 14,27202 & 2,01 & 0,25 \\
\hline & 23,03858 & 21,00362 & 19,50044 & 1,71 & 0,57 \\
\hline Exportações de bens e serviços & & & & & \\
\hline Importações de bens e serviços & 10,66464 & 12,5144 & 11,89062 & 4,75 & 2,99 \\
\hline
\end{tabular}

Fonte: WorldBank Database, 2017

Entre 2008 e 2017 a média de crescimento do PIB americano foi de 1,36\% ao ano. (UNCTAD, 2017). Embora o país tenha conseguido superar os anos de recessão pós crise a partir de 2012, os dados sobre a dinâmica desse crescimento ao longo dos anos são interessantes. Como se vê na Tabela a participação do consumo no PIB, principalmente das famílias, continua alto. No entanto entre 2008 e 2016 observa-se uma queda no ritmo desse crescimento, com a taxa caindo de $2,8 \%$ para $1,59 \%$.

Outro dado importante é sobre a Formação Bruta de Capital. Em 2016 ele representava apenas $19 \%$ do PIB e cresce entre 2008 a 2016 a apenas $0,57 \%$ ao ano. Esse dado mostra claramente a dificuldade americana em expandir os investimentos, por exemplo, via indústria ou infraestrutura.

Em termos dos dados sobre a Balança Comercial tem-se que em 2014 a participação das importações no PIB diminui e a taxa de crescimento das importações é de 1,77\% apenas entre 2008 e 2016 . Ou seja, os EUA depois da crise passam a importar a um ritmo menor que o período pré-crise. As exportações também crescem a um ritmo menor, apenas 2,99\%. 
Ainda que com taxas de crescimento mais modestas os EUA recebem, mesmo depois da crise, um aporte robusto de IDEs de todo o mundo. Houve uma fase de estagnação, mas depois de 2014 há uma expansão dos IDEs para os EUA. (Unctad, 2017)

Outros dados importantes a serem considerados são os dados de emprego, salário e produtividade. Com relação a taxa de emprego, como porcentagem da população em idade ativa, tem -se uma queda. Em 2002 a taxa era de 74\%, já em 2010 caiu para 66,7\% e em 2015 ficou em 68,7\%. (OECD, 2017). Entre os jovens a taxa de emprego caiu de 59\% para 49\% entre 2000 e 2015. Acompanhando a redução do emprego principalmente para os jovens temse uma dificuldade em ampliar a renda de determinadas faixas de rendas médias. O gráfico abaixo apresenta a queda dos rendimentos das camadas média americanas, inclusive comparativamente a China:

\section{Gráfico 1: Rendas e ganhos reais médios nos EUA e na China}

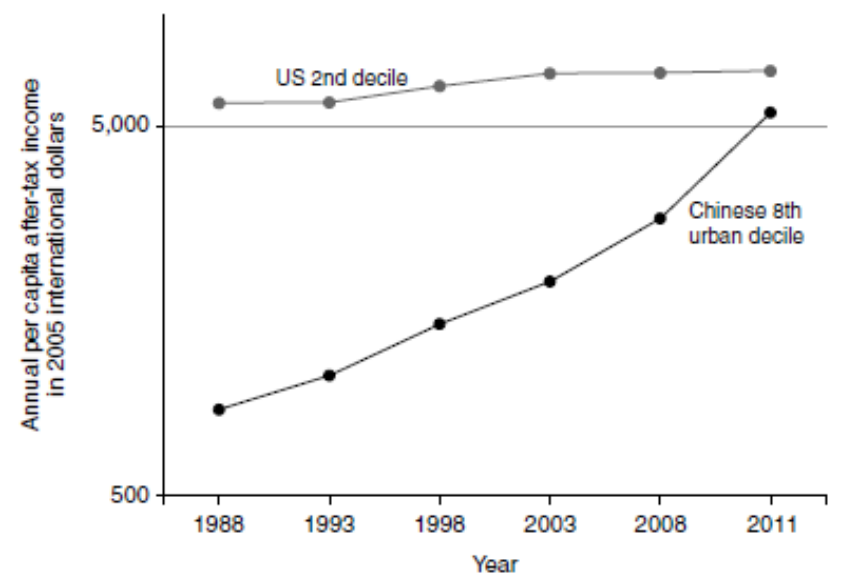

Fonte: MILANOVIC, 2016.

O gráfico de Milanovic (2016) mostra a convergência das rendas chinesas e americanas entre 1988 e 2011 e a mudança anual real per capita da renda após a cobrança de impostos para o mesmo segmento de renda. Entre 1988 e 2011 para as pessoas nos EUA situadas no segundo decil de renda, que corresponderia na China ao oitavo decil de renda urbana, observa-se que apesar de ainda possuir uma renda maior em 2011, houve uma diminuição considerável do gap entre eles ao longo dos anos. A parcela de renda da camada americana mantem-se estagnada ao longo de todo o período.

A análise de Milanovic (2016) sobre a desigualdade dentro dos países procura enfatizar as consequências da globalização tanto para economias centrais, como a americana, como para emergentes, como a chinesa. Segundo o autor a renda das camadas médias caiu 
não apenas dos EUA, mas em outras economias centrais, como a inglesa. Teria ocorrido uma forte concentração de riquezas no topo nessas economias, enquanto a renda média seguiu estagnada, conformando um grupo que segundo o autor seriam os "perdedores da globalização".

Mesmo com a queda do emprego e dos rendimentos das camadas médias, a economia americana segue mantendo uma alta produtividade do trabalho, que inclusive aumentou do período pós crise de 1 para 1,04. (OECD, 2017).

- China pós crise de 2008

Ao contrário dos Estados Unidos, na China o período posterior a crise é marcado pela manutenção do crescimento a níveis elevados ainda que a taxas menores comparativamente à primeira década do século XXI. Observa-se a continuidade do aumento da renda média e também dos salários, além da produtividade.

Desde o início de século XXI as taxas elevadas de crescimento chinesas (em média $10 \%$ ao ano) foram acompanhadas pela entrada do país em um ciclo de crescimento baseado na expansão dos investimentos em infraestrutura e indústria pesada, principalmente via altos investimentos estatais, projetos de construção e urbanização. Os impactos desse ciclo foram significativos para a economia mundial, com a ampla demanda por insumos primários, desde matérias-primas para indústria, como minério de ferro e cobre, até recursos energéticos essenciais, como o petróleo.

Até hoje, mesmo depois da crise, esse imperativo vem moldando o processo de expansão da China por diversas regiões do mundo, com o governo chinês e as empresas estatais promovendo abordagens em regiões que dispõem de amplos recursos naturais, como a América Latina e a África. Foi inclusive o período da forte expansão das exportações dos países periféricos que permitiu a melhora do Balanço de Pagamentos de países como Brasil, Venezuela e diversos africanos.

No entanto, tal conjuntura começa a apresentar sinais de esgotamento já no fim da década, com a crise de 2008. Nesse contexto, a China sentiu os efeitos da retração econômica mundial, principalmente devido à queda da demanda externa dos países industrializados, como Europa e Estados Unidos. A partir daí o país apresentaria taxas de crescimento menos expressivas e enfrentaria os efeitos adversos da crise mediante uma política anticíclica voltada 
para a continuidade do aumento dos Investimentos estatais na indústria pesada, construção e urbanização, na tentativa de sustentar a demanda interna e compensar a diminuição da demanda externa. (SHANG-JIN WEI, 2016; OCAMPO e ERTEN , 2013).

Mas, além disso, nos anos mais recentes, no que poderia ser apontado como o mais recente ciclo de crescimento chinês, o país estaria buscando um regime de crescimento menos intensivo da indústria pesada e em capital e mais baseado em uma ampliação da demanda interna, tornando a economia mais sustentada no mercado doméstico. (CINTRA et al, 2015). A Tabela abaixo apresenta alguns indicadores da economia chinesa de 2000 a 2017.

Tabela 2: China: Indicadores (2000-2017)

\begin{tabular}{|l|r|r|r|r|r|r|}
\hline & \multicolumn{2}{l|}{ \% do PIB PIB crescimento anual } \\
\hline & 2000 & 2008 & 2016 & $2000-2008$ & $2008-2016$ \\
\hline Despesas de consumo final das famílias & 46,2 & 36,4 & 39 & 8,87 & 8,51 \\
\hline Despesas de consumo final do governo & 16,63 & 13,2 & 14,4 & 10,76 & 9,06 \\
\hline Formação Bruta de Capital Fixo & 33,43 & 40,1 & 42,9 & & 12,83 & 11,18 \\
\hline & & & & & & \\
\hline Exportações de bens e serviços & 21,23 & 32 & 19,6 & 24,82 & 7,16 \\
\hline Importações de Bens e serviços & 18,51 & 24,9 & 17,4 & 24,12 & 9,43 \\
\hline
\end{tabular}

Fonte: WorldBank Database, 2017

A Tabela mostra dados relacionados ao PIB chinês pela ótica da despesa/consumo: despesas das famílias, do governo, FBCF e ainda exportações e importações. Embora não haja grandes transformações desde os anos 2000 até hoje com relação aos determinantes do crescimento do país, algumas mudanças aparecem no período pós crise de 2008.

Em 2008 as despesas de consumo das famílias correspondiam a 36,5\% do PIB. Já em 2016 as despesas das famílias aumentam para 39\% do PIB. Apesar do aumento, no período entre 2008 e 2016 o ritmo de expansão desse gasto permanece em torno de $8 \%$. Certamente não é possível afirmar que haja uma substituição do investimento pelo consumo como principal motor do crescimento chinês, uma vez que, como também se observa na Tabela, a Formação Bruta de Capital fixo se mantem alta (42,9\% do PIB em 2016) embora crescendo a uma taxa menor (11,18\% ao ano).

Há historicamente uma forte correlação entre Investimento e crescimento do PIB na China, sendo essa variável percebida como o grande motor do crescimento desde a instauração da República Popular. (Medeiros, 2012). Desde 2008 a participação do Investimento no PIB permanece alta, como mostra o gráfico abaixo. No entanto, quando se observam as taxas de expansão do investimento e do consumo das famílias observa-se que há uma maior convergência com relação ao crescimento do PIB (Gráfico b). 
Gráfico 2: China - Investimento (\% do PIB) e Taxa de expansão do PIB (2000-2015) (a); Taxa de expansão do investimento, Taxa de expansão do consumo das famílias; Taxa de expansão do PIB (2000-2015) (b)

(a)

(b)
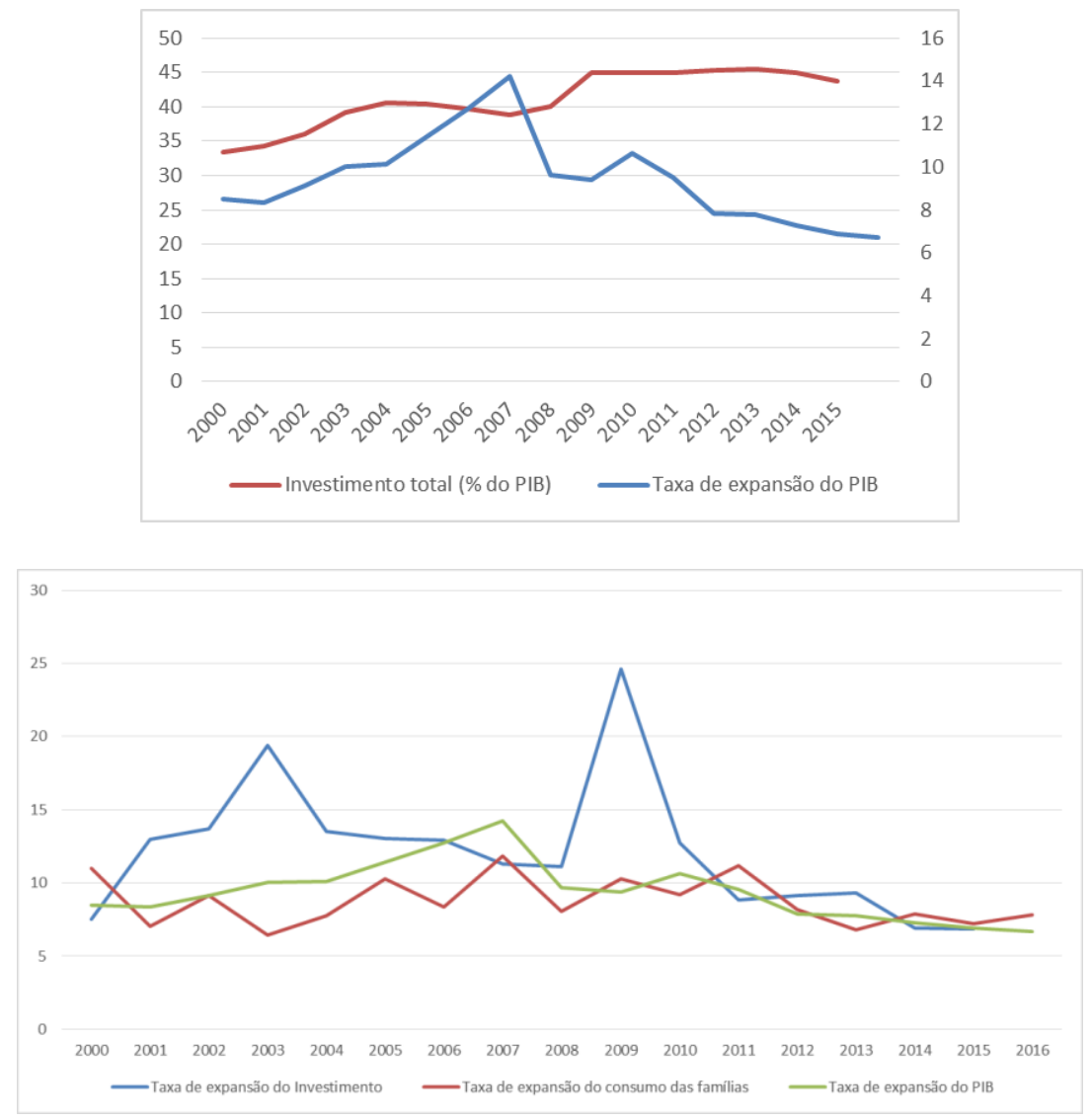

Fonte: WorldBank Database, 2018

No segundo gráfico é possível notar que a partir de 2008 há uma maior aproximação entre as médias de expansão das taxas dos determinantes do Produto. A expansão do investimento e consumo das famílias cresce a uma taxa bastante próxima a taxa de crescimento do PIB.

Além das variáveis Investimento e Consumo, outro dado interessante é o de comércio externo. Observa-se depois de 2008 a queda da participação das exportações no PIB e a queda do ritmo da expansão das exportações (7,16\% entre 2008 e 2016). No caso das importações o peso é ainda menor (18\%). Os dados mostram que, em termos líquidos, o comércio exterior contribuiu pouco para a expansão do PIB, muito menos que os Investimentos.

O dado interessante e novo que aparece na análise do perfil do investimento chinês hoje é que ele vem acompanhado de outros gastos importantes, como em Pesquisa e Desenvolvimento. Dados da OECD mostram que a China é hoje o segundo maior investidor 
em Pesquisa e Desenvolvimento, atrás apenas dos EUA. De 2008 até 2015 o gasto sai de 150 bilhões para quase 400 bilhões. Nesse ritmo de expansão é possível que a China ultrapasse os EUA como maiores investidores em Pesquisa e Desenvolvimento. Atualmente os EUA gastam cerca de 460 bilhões em P\&D. (OECD, 2017).

Essa realidade do padrão de crescimento chinês sinaliza também para o fato de que um processo de catching up tecnológico está em curso no país. Há uma forte preocupação com a modernização tecnológica e industrial. A participação da indústria no PIB na China vem caindo após um longo período de expansão: em 2008 a participação da indústria era de 41\% e em 2015 caiu para 34\%. Em seu lugar observou-se a expansão dos Serviços, o que pode ser analisado como parte de um processo de maior complexificação da economia chinesa, com a forte expansão de atividades como o e-commerce e indústrias mais complexas dentro da chamada Indústria 4.0. Recentemente a China lançou o que pode ser visto como o mais novo Programa Industrial do país, o “China Manufacturing 2025”. O projeto prevê a modernização da indústria e o desenvolvimento de setores mais avançados até 2025, como os que possuem conexão com serviços e tecnologia verde, ou ligados a próxima geração de TI, robótica, equipamento espacial e aviação e biomedicina.

Como sugere relatório da OECD (2015) "Trade in value added: China", uma mudança estrutural significativa ocorreu na China nas últimas duas décadas. De um exportador de produtos de baixo valor agregado, como têxteis, o país passou a grande exportador de produtos high-tech. Além disso em diversos setores essa mudança foi acompanhada de um aumento no valor agregado doméstico, refletindo uma grande habilidade em subir nas cadeias de valor. Em 2008 o valor adicionado doméstico das exportações chinesas era de 68,33\%, já em 2014 passou para 70,65\%. (OECD, 2017).

Certamente, mesmo depois da crise, não houve uma interrupção dos investimentos em infraestrutura. Investimentos em ferrovias, sistemas de trem de alta velocidade e ainda a expansão da internet no país continuam com força. Segundo Dic Lo (2016) essa expansão do investimento deu-se com base na expansão do gasto do governo, embora a expansão da dívida do governo central seja menor comparativamente ao período que seguiu a crise asiática no fim dos anos 90. Segundo o autor expandiu-se bastante outros mecanismos de financiamento com uma ampla variedade de inovações financeiras, além de gastos de governos locais. Segundo o autor essa expansão monetária e financeira pode inclusive ser um complicador de longo prazo para a economia chinesa. (DIC LO, 2016) 
Importa ressaltar que a expansão monetária via diversificação de instrumentos financeiros e dívida de governos locais não sinaliza um sinal de crise na indústria. Segundo Dic Lo (op cit) a taxa de lucro na indústria na China não cai desde o fim dos anos 90 . $\mathrm{O}$ crescimento chinês segue baseado em um crescimento com expansão produtiva e aumento na produtividade do trabalho, refletindo um modelo que o autor denomina como "Golden Age"6, em uma referência a fase do ciclo de expansão produtiva do pós segunda guerra.

Permanece também no pós 2008 a expansão produtiva com aumento de produtividade e menos pelo uso da oferta de trabalho, com a própria produtividade aumentando não pelo aumento da exploração do trabalho e sim por um modelo cada vez mais capital intensivo. (DIC LO, 2016).

Observa-se a melhora dos padrões de vida e capacidade de geração de empregos, em que pese a continuidade diferença de renda. Destacam-se a importância dos esforços nos últimos anos por parte do governo de expansão dos sistemas de saúde universais ${ }^{7}$ e fortalecimento dos sindicatos ${ }^{8}$, que contribuem para aumentar o nível de vida e o poder de barganha dos trabalhadores e consequentemente para o crescimento dos salários.

No gráfico abaixo percebemos o aumento de salários desde 2003 a 2013:

\footnotetext{
${ }^{6}$ Embora venha dando continuidade a seu modelo "Golden age" como sugere Dic Lo, um fato importante depois da crise é que há uma pressão que parte de grupos ligados a setores financeiros em torno do Estado. $\mathrm{O}$ investimento imobiliário tipo bolha pode ter agravado o investimento produtivo e isso seria a causa da desaceleração do PIB nos últimos anos. Opções de investimentos financeiros, ligados ao aumento da possibilidade de financiamento e lucro geraram reclamações por parte do setor produtivo depois de 2008 . Segundo o autor a China estaria em um momento crucial em que dois modelos estariam em jogo: a continuidade do Golden Age ou a maior flexibilização via políticas de caráter mais neoliberal. (Dic LO, 2016)

7 A questão da expansão da proteção social chinesa é um tema ainda pouco analisado. Com o processo de abertura e fim do regime socialista maoísta ocorreu uma desarticulação quase completa da rede de proteção chinesa, como educação e saúde gratuitos para todos, assim como direitos de seguridade e trabalhistas. Houve com Deng Xiaoping um processo de retirada desses direitos, com a população chinesa passando a ter que pagar por ensino (básico e universitário) e saúde. Nas últimas décadas, principalmente a partir dos anos 2000, o governo vem atuando no sentido de reverter esse processo, promovendo políticas de expansão da educação gratuita (o ensino básico já voltando a ser gratuito para a maioria da população) e formas de financiamento público da saúde via sistemas de credito.

${ }^{8}$ A China possui um monopólio do sindicalismo através da organização All China Federation of Trade Unions. Nos últimos anos tem-se observado um aumento do número de greves no país que inclusive contribui como fator de pressão pelo aumento dos salários. A ACFTU não organiza as greves, mas tenta intermediar os conflitos. (Lin, 2016) (Hernández, 2016).
} 
Gráfico 3: China - Média salarial das pessoas empregadas em unidades urbanas 20032013 (Renminbi)

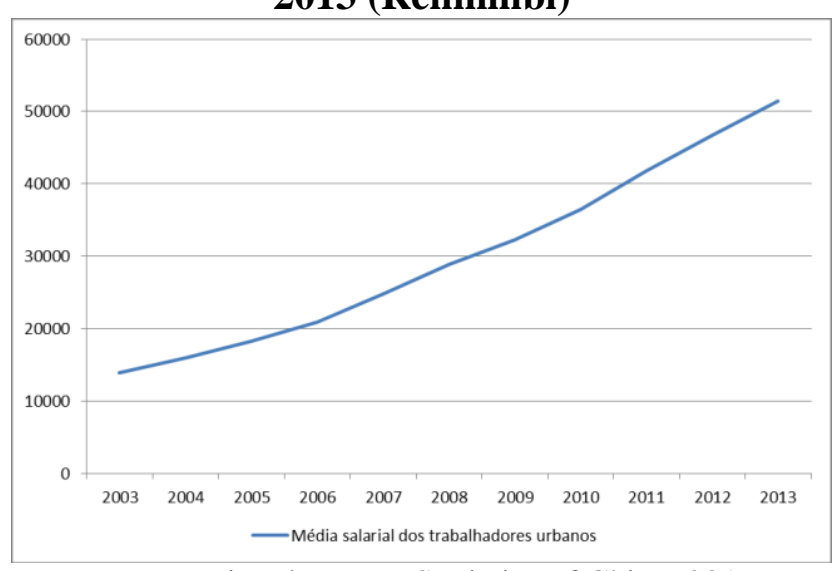

Fonte: National Bureau Statistics of China, 2017.

Como se observa houve crescimento do nível salarial ao longo dos anos desde 2008. Vale ressaltar que na China há uma vasta diversificação e complexidade do mercado de trabalho, principalmente nas cidades. Em meados dos anos 90, por exemplo, após o fim do danwei e das privatizações e demissões em massa no setor público, houve um crescimento expressivo do emprego informal nas regiões urbanas. Segundo Morais (2011), é possível afirmar que o salário mínimo dos trabalhadores registrados tem aumentado, porém houve um crescimento também na diferença salarial entre os trabalhadores formais e informais, ou seja, aqueles que trabalham sem registro de residência urbano.

\section{3 - China e EUA: interdependência econômica}

Na primeira década após a crise as relações entre a economia americana e chinesa permanecem fortes do ponto de vista principalmente comercial. Os dois países convivem com uma alta complementaridade nas exportações e importações. Embora a crise tenha abalado o comércio mundial como um todo, ainda se observa o ritmo de seu crescimento acima do crescimento do produto mundial o que indica a continuidade da globalização produtiva e integração comercial. Entre 2010 e 2016 o crescimento mundial foi de 2,6\% ao ano, enquanto a taxa de crescimento das exportações ficou em 4,15\% entre 2010 e 2016 e de $4 \%$ nas importações no mesmo período. (UNCTAD, 2017).

Também na primeira década pós-crise as exportações e importações chinesas continuaram crescendo a um ritmo bem mais elevado do que as americanas, a uma taxa de 
15,28\% para as exportações e 14,17\% das importações, enquanto os EUA registraram 4,4\% e $4,3 \%$, respectivamente.

O déficit comercial americano com a China continua. Como mostrou Pinto (2010), após a crise observou-se uma queda menor das exportações americanas comparativamente as importações a partir da China, o que levou a uma queda do déficit de 277 bilhões em 2009 para 201 bilhões em 2010. No entanto, após esse período o que se observa é a volta do aumento do déficit, chegando a quase 400 bilhões em 2016, como mostra o gráfico abaixo:

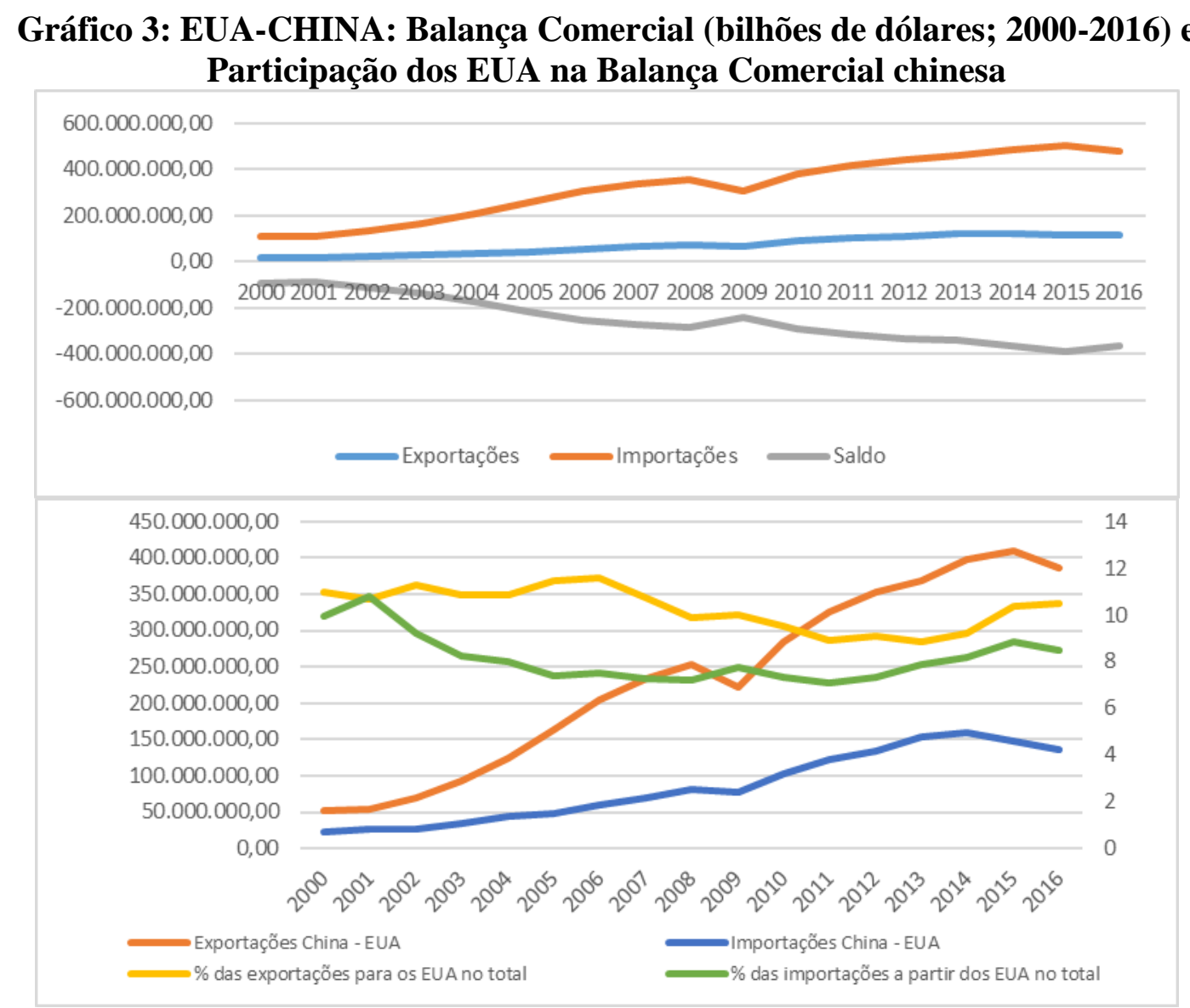

Fonte: UnctadStat, 2017

O retrato do comércio EUA-China reflete a continuidade da complementaridade ao menos do ponto de vista comercial. O mercado americano ainda é importante para a China, apesar de representar apenas $10 \%$ do total exportado pelo país asiático e apenas $8 \%$ do total importado em 2016. As importações chinesas também são fundamentais para os EUA. Os debates em torno das disputas comercias no âmbito da OMC, como as acusações de dumping e a postura de Trump nas eleições a favor de um maior protecionismo com relação à China refletem essa realidade. 
Outro fato importante é a continuidade do aumento das exportações chinesas de maior conteúdo tecnológico para os EUA. Depois da crise esse movimento não cessou. A Tabela abaixo mostra os produtos que compõem a Balança comercial entre EUA e China

Tabela 3: Balança Comercial China-Estados Unidos (2008; 2016/ bilhões de dólares)

\begin{tabular}{|l|r|r|r|r|}
\hline China: Importações a partir dos Estados unidos & 2008 & 2008 & 2016 & 2016 \\
\hline TOTAL & 81.585 .556 .125 & $\%$ & 135.120 .133 .073 & $\%$ \\
\hline alimentos e bebidas & 11.197 .802 .284 & 13,7 & 19.831 .469 .912 & 14,7 \\
\hline fornecimentos industriais & 30.309 .709 .039 & 37,2 & 41.228 .717 .392 & 30,5 \\
\hline combustíveis e lubrificantes & 720.332 .777 & 0,9 & 2.276 .211 .133 & 1,7 \\
\hline bens de capital e suas partes e acessórios & 28.606 .844 .681 & 35,1 & 34.696 .712 .286 & 25,7 \\
\hline equipamentos de transporte & 8.367 .359 .142 & 10,3 & 31.179 .517 .187 & 23,1 \\
\hline bens de consumo & 2.337 .993 .683 & 2,9 & 5.490 .292 .417 & 4,1 \\
\hline outros bens & 45.514 .519 & 0,1 & 417.212 .746 & 0,3 \\
\hline China: Exportações para os Estados Unidos & & & & \\
\hline OOTAL & 252.843 .530 .635 & $\%$ & 385.677 .759 .424 & $\%$ \\
\hline alimentos e bebidas & 4.365 .438 .268 & 1,73 & 6.203 .214 .004 & 1,6 \\
\hline fornecimentos industriais & 42.358 .507 .677 & 16,75 & 59.883 .214 .570 & 15,5 \\
\hline combustíveis e lubrificantes & 2.137 .095 .498 & 0,85 & 1.138 .666 .612 & 0,3 \\
\hline bens de capital e suas partes e acessórios & 98.695 .404 .971 & 39,03 & 157.003 .043 .030 & 40,7 \\
\hline equipamentos de transporte & 14.627 .130 .588 & 5,79 & 24.629 .991 .782 & 6,4 \\
\hline bens de consumo & 90.479 .476 .091 & 35,78 & 136.370 .494 .213 & 35,4 \\
\hline outros bens & 180.477 .542 & 0,07 & 449.135 .213 & 0,1 \\
\hline
\end{tabular}

Fonte: UNComtrade Database, 2017. Classificação BEC

Como se observa a China continua importando em sua maioria produtos industrializados a partir dos EUA, como bens de capital e equipamentos de transporte. No entanto houve uma queda importante entre 2008 e 2016 das importações de alguns bens como "fornecimentos industriais" de 37\% para 30\%; de "bens de capital", de 35\% par 25\%; com apenas os "equipamentos de transporte" tendo sua participação aumentada de $10 \%$ para $23 \%$. Bens não industriais como combustíveis e alimentos tiveram sua participação aumentada no período.

Do lado das exportações chinesas para os EUA mantem-se a alta participação da exportação de bens de capital e bens de consumo e a queda das exportações de combustíveis e alimentos.

Com relação aos fluxos de investimento direto tem-se que, segundo os dados da Unctad, em 2008 a China investiu cerca de 500 milhões de dólares nos EUA e em 2012 1,3 bilhão. Os Estados Unidos por sua vez investiram em 2008 2,9 bilhões na China e em 2012 2,5 bilhões. Mas talvez a maior mudança com relação aos IDEs entre os dois países seja a expansão do investimento chinês nos EUA. Em 2009 ele era menos de 1 bilhão e já em 2015 
chega a quase 15 bilhões. O movimento sinaliza uma grande mudança na China pós 2009, ou seja, a forte expansão dos investimentos não só para os EUA mas em todo o mundo. Em 2016 os IDEs chineses já eram de 217 bilhões, quase se aproximando do nível dos EUA.

\section{Gráfico 4: China - Investimentos Externos Diretos (para fora) bilhões de dólares (2006- 2016)}

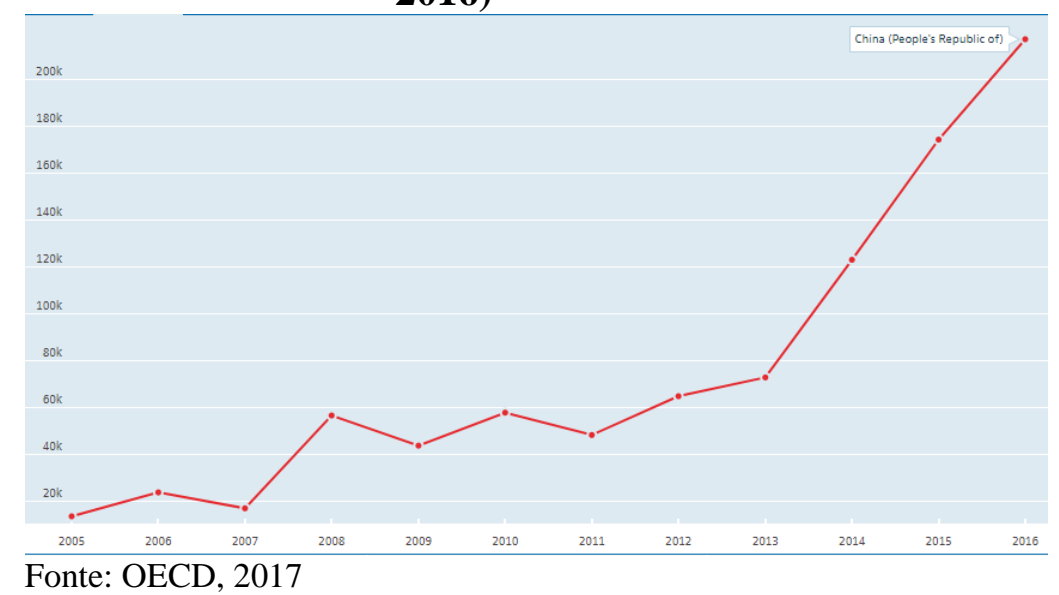

Ao longo de mais de trinta anos a China foi receptora de uma quantidade crescente de investimentos externos, absorvendo um total de mais de 1 trilhão de dólares de IDEs entre 1979 e 2010. Mas após a consolidação do crescimento econômico a situação se inverte e os chineses avançam expandindo seus próprios investimentos externos, com as empresas do país expandindo-se para diversas partes do mundo, apoiadas em um volume substancial de reservas acumuladas. (SHAMBAUGH, 2013).

Com relação as conexões financeiras entre as duas economias também aparecem alguns dados novos depois da crise de 2009.

O quadro geral pós crise de 2008 é marcado, segundo Goldstein et. al. (2017) pela queda dos fluxos de capitais transfronteiriços globais (incluindo empréstimos, compras de ações e bônus e investimento direto estrangeiro) acentuada de $65 \%$ desde 2007, passando de 12,4 trilhões de dólares para 4,3 trilhões entre 2007 e 2016. Quase metade dessa redução diz respeito a empréstimos e atividades bancárias. Ainda assim, segundo os autores, isso não significa o fim da globalização financeira, mas uma mudança de seu perfil, agora muito mais sensível ao risco e mais racional, no que seria uma versão mais resiliente da integração financeira. (GOLDSTEIN et. al., 2017).

Houve de fato uma redução dos fluxos financeiros entre os países centrais (USA e Europa) devido as grandes perdas depois da crise, principalmente dentro da eurozona. Muitos 
bancos passaram a preferir negócios domésticos e novas regulações criaram desincentivos. Por outro lado, ao mesmo tempo países em desenvolvimento, como a China e outas economias avançadas, como Japão e Canadá, expandiram seus empréstimos externos:

\begin{abstract}
"Some banks from developing and other advanced economies, however-notably Canada, China, and Japan - are expanding abroad. Canadian and Japanese banks have doubled foreign claims since 2007 by $\$ 2.3$ trillion, bringing the total to $\$ 5.3$ trillion in 2016 (\$1.4 trillion for Canada and \$3.9 trillion for Japan). China's four largest banks have increased foreign lending by more than ten times, from $\$ 86$ billion in 2007 to $\$ 1$ trillion in 2016. And China's foreign bank lending could continue to grow: foreign assets are only 9 percent of total bank assets in China, compared to 20 percent or more for banks in advanced economies. This suggests more scope for Chinese banks to expand globally, if they follow the path of the world's other large banks. (GOLDSTEIN et. al., 2017).
\end{abstract}

Essa mudança é importante pois sinaliza uma postura chinesa mais ativa com relação a diversificação de seus ativos e disposição de expandir-se para fora, seja dentro de uma ideia de diversificação de suas reservas acumuladas seja como parte de uma estratégia política de afirmação a nível global. Em 2009 o volume de reservas chinesas chegou a 2,4 trilhões de dólares. Em 2014 elas já eram de 4 trilhões. Em 2016 houve uma queda para 3,3 trilhões e para 3 trilhões no fim de Novembro a partir de alguns controles impostos pelo governo chinês. (OECD, 2017).

Como se sabe boa parte das reservas chinesas é utilizada na compra de títulos do Tesouro americano. Como mostrou Pinto (2010) em 2001 os chineses possuíam apenas 78,6 bilhões de dólares em títulos do tesouro, que respondia por apenas 7,6\% do total. Houve um crescimento muito significativo do peso da China como detentora destes títulos, um crescimento de $1.375 \%$, chegando em 2010 com os chineses possuindo $26 \%$ dos títulos americanos que correspondia a mais de 1 trilhão de dólares.

A partir de 2011 os chineses continuam comprando esses papéis e em 2017 (Junho) possuem 1,146 trilhões em títulos americanos, com os japoneses ocupando a segunda posição como detentores.

O que chama a atenção é que entre 2011 e 2017 o ritmo de crescimento dos títulos em posse dos chineses diminuiu consideravelmente comparativamente ao período anterior à crise. A média foi de 0,12\% com destaque para o fato de que em 2016 houve uma queda brusca da compra de títulos por parte dos chineses com o Japão assumindo a liderança como maior detentor. Em Outubro de 2017 a participação dos chineses no total de títulos caiu para 
18,7\%, parcela bem menor comparado a de quase $30 \%$ que chegou a ocupar em anos anteriores. (Department of the Treasury/Federal Reserve Board, 2017).

\section{4 - Estados Unidos e China: relações interestatais}

Segundo Callinicos (2014) teria perpetuado entre alguns autores a ideia de "momento unipolar" no fim da Guerra Fria, relacionada ao fato de que os EUA tinham uma extraordinária superioridade militar sobre os demais poderes combinados. $\mathrm{O}$ autor afirma que já naquela época havia uma contradição entre a supremacia militar do Pentágono e o contínuo declínio econômico relativo dos EUA, camuflado por um boom que já vinha sendo impulsionado por uma bolha financeira - inicialmente no mercado de ações e então, em meados dos anos 2000, no imobiliário (Brenner, 2002, apud Callinicos, 2014).

A crise de 2008 teria elucidado as maiores divergências entre as taxas de crescimento americanas e países emergentes, como a China, e estaria possibilitando um estreitamento do hiato em capacidade militar entre os EUA e o resto.

Em 2013, o orçamento de defesa dos EUA era de imensos US\$ 600,4 bilhões, ainda eclipsando o de concorrentes próximos, China (US\$ 112,2 bilhões), Rússia (US\$ 68,2 bilhões), Arábia Saudita (US\$ 59,6 bilhões) e Grã-Bretanha (US\$ 57 bilhões). Desde 2008 o gasto com defesa elevou-se bruscamente em algumas das principais economias "emergentes de mercado", ao mesmo tempo em que estagnou ou contraiu-se no ocidente.

Nesse sentido, por mais que haja complementaridade do ponto de vista comercial entre as economias americana e chinesa, as trajetórias dos dois países pós crise de 2008 parecem reforçar um acirramento da competição interestatal, quando se analisa a forte expansão da força bélica, principalmente dos EUA mas também da China.

Segundo Callinicos (2014) o imperialismo moderno é um sistema de concorrência e rivalidade intercapitalista. Isso significaria que

\footnotetext{
"o equilíbrio de poder encontra-se em constante deslocamento, criando as circunstâncias para novos conflitos. O desenvolvimento geopolítico crucial na primeira metade do século XX foi o deslocamento no poder relativo desde a GrãBretanha, até então o Estado capitalista dominante, para os EUA, e a Alemanha; hoje, outro deslocamento no poder relativo vem ocorrendo entre os EUA e a China. Mudanças dessa natureza, Lenin destacou, tornam impossível a pacífica integração transnacional dos capitais que Karl Kautsky denominou "ultraimperialismo" e que Michael Hardt e Toni Negri mais recentemente chamaram de "Império": a
} 
redistribuição de poder entre os Estados mina os acordos que seriam necessários para fazer tal integração funcionar". (Callinicos, 2014).

Mesmo com os Estados Unidos permanecendo como centro de comando do capitalismo global, algumas crises recentes impõem aos tomadores de decisão nos EUA novas estratégias de enfrentamento da competição global. Uma destas crises - ou se não uma crise ao menos um conflito potencial - seria justamente a crescente concorrência inter-Estados na Ásia Oriental e a estratégia americana no Pacífico em resposta ao poder em expansão da China.

Assim, do ponto de vista das relações interestatais haveria uma clara competição em termos estratégico e militares entre EUA e China. O caso das disputas em torno do Mar do Sul da China são um exemplo disso. A região é fundamental para a China e o país vem expandindo sua força bélica e principalmente marítima voltada para a proteção e expansão da região. Enquanto isso a presença bélica americana no Pacífico continua alta.

Apesar da China estar expandindo seus recursos militares principalmente na Ásia, seu foco não seria mais apenas regional. Desde a crise de 2008, embora ainda evitando a postura de enfrentamento bélico, a China aparece expandindo sua força por meio da continuidade da expansão do orçamento militar e pela abertura da primeira base militar chinesa criada na África.

Aliado a isso a estratégia de expansão do Investimentos Externos e os grandes projetos da era Xi Jinping, como o One Belt One Road (OBOR), representariam certa disposição chinesa em projetar-se externamente. O Projeto OBOR representa um ambicioso plano de infraestrutura anunciado em 2013 e que envolve mais de sessenta países, entre eles asiáticos, europeus e africanos. Tudo será financiado por um fundo criado em 2014 especificamente para a estratégia, com investimentos dos principais bancos estatais, em particular o State Administration of Foreign Exchange, o China Investment Corporations, o EximBank e o China Development Bank. O fundo já tem um capital de 40 bilhões de dólares para ser utilizado e, segundo algumas fontes, o governo chinês estaria comprometido com financiamentos que podem chegar a 1 trilhão de dólares na próxima década.

A estratégia OBOR representa, segundo o discurso do governo, objetivos de promoção da cooperação regional, fortalecimento das trocas comerciais e aumento da prosperidade econômica de todos os países ao longo da rota. Além disso, insere-se no apelo recente de Xi 
Jingping ao fortalecimento de um mundo multipolar e de ampliação da globalização econômica com cooperação regional e integração dos mercados.

Mas para além do discurso oficial o projeto insere-se dentro de um quadro maior dos objetivos geopolíticos e também econômicos da China. Em termos geopolíticos o projeto representa uma postura de política externa mais assertiva da China com Xi Jinping e a estratégia de fortalecer sua posição com relação aos países vizinhos e em regiões estratégicas na Ásia Central e África e ampliar seus espaços de influência.

Nesse contexto, do ponto e vista das relações interestatais entende-se que a China se apresenta atualmente como um grande ator em termos de projeção global, fenômeno que suscita importantes debates sobre as novas determinações do imperialismo no século XXI.

A conjuntura pós crise elucidou de um lado as contradições da acumulação de capital a nível global, que compromete a expansão e distribuição da renda nos EUA. Por outro lado, não interrompeu o crescimento e expansão da China, muito pelo contrário, colocou o país em uma nova rota de projeção externa, com impactos em todo o mundo. Essa nova configuração marca, a nosso ver, o acirramento do imperialismo americano que tende a responder de forma ativa à ascensão chinesa no mundo.

Os desafios que se apresentam diante dessa nova conjuntura seriam nesse sentido tanto teóricos como políticos, ou como afirma Callinicos:

Understanding imperialism requires close empirical study since it concerns a historical phenomenon that has complex characteristics and is subject to change. But it also demands theoretical reflection on what makes the imperialism we encounter today historically distinctive. (CALLINICOS, 2009).

\section{5 - Conclusões}

Dez anos após a crise de 2008 a economia mundial, principalmente as economias avançadas, parecem não ter recuperado os patamares de crescimento. Do ponto de vista da acumulação de capital em escala global predomina na conjuntura mundial a dificuldade de expansão da esfera produtiva, principalmente no Ocidente, aliada a continuidade da força política do capital fictício (Marx, 1884). Observa-se de um lado a continuidade das políticas de pouca regulação dos mercados financeiros, seja nos Estados Unidos ou na Europa, em um 
quadro em que o Estado Nacional tem pouca ou quase nenhuma capacidade de implementar políticas voltadas a expansão do produto e da renda.

O padrão dólar flexível, criado a partir da ação unilateral norte americana, impôs ao mundo não apenas ajustes recessivos, mas também um quadro estrutural em que a dinâmica de financeirização é incompatível com a expansão produtiva e a distribuição da renda. Por mais que não se vislumbre o fim lógico desse modelo em termos monetários, do ponto de vista distributivo ele parece estar alcançando seus limites, em um quadro parecido com o contexto de crise do padrão libra ouro antes da Primeira Guerra Mundial, como retratou Polany em “A Grande Transformação".

A maior prova disso é a dificuldade da economia americana em expandir a renda dos seus próprios trabalhadores, um quadro que se assemelha às dificuldades enfrentadas pela Inglaterra ainda no início do século XX, em um cenário de crise do padrão monetário e fim do Império britânico no mundo.

A sociedade americana continua rica, mas em uma inércia marcada pela concentração da renda e pelas poucas chances de melhores condições de vida a grande parte de seus cidadãos, quadro que instaura na sociedade tensões sociais importantes, por mais que a força do dólar não tenha sido abalada pela crise e por mais que o déficit americano não seja um problema em si.

De 2008 em diante a economia americana cresce mais devagar e, embora o consumo seja a maior parte do PIB o ritmo de seu crescimento é mais lento. Além disso o déficit americano agora não está ligado apenas ao aumento das importações, como sugeriu Panitch e Gindin (2013), mas também a queda nas exportações, que crescem a um ritmo também menor, de $7 \%$ ao ano.

Esse quadro não representa um rompimento com relação ao período anterior, a não ser pelo fato de que reafirma a posição americana de importador líquido e com grandes dificuldades de avançar em termos produtivos e industriais. Cabe questionar até que ponto a baixa renda interna das camadas médias vai conseguir sustentar uma sociedade baseada no consumo.

A nosso ver os EUA tem procurado superar estas contradições menos por meio de uma contestação a globalização e mais mediante a afirmação de seu poder imperial, seja pela via da manutenção de uma indústria de defesa e aparato militar únicos no mundo, seja pelo acesso 
a recursos primários estratégicos, quadro que sinaliza para um acirramento do imperialismo ou uma reedição do neocolonialismo.

Mas talvez a maior novidade destes tempos pós crise de 2008 esteja mesmo do outro lado no mundo, na China.

O país não foi abalado pela crise e sustentou taxas de crescimento altas em um cenário de incerteza. Além disso o país vem dando continuidade a política de distribuição e aumento da renda, geração de emprego e inovação tecnológica, alcançando a cada ano melhores posições nas cadeias globais de valor, ressaltando que, embora ainda persista a participação estrangeira no valor agregado das exportações, ela vem diminuindo, com o conteúdo doméstico representando $70 \%$.

Todo esse processo de mudança estrutural chinesa foi fundamental para o período de bonança pré crise, tanto para os EUA como para o mundo todo. A expansão chinesa, como sugeriu Panitch e Gindin, representou a continuidade da produção manufatureira global consumida pelo mercado americano, inclusive com a garantia de preços baixos. Além disso a acumulação de reservas chinesas permitiu a compra dos títulos do tesouro americano, perpetuando a lógica monetária da economia americana.

Embora no período pós crise essas relações não tenham sido interrompidas, agora encontram-se em outro patamar, relacionado principalmente a expansão da China.

Dez anos após a crise, além de poupadores os chineses são também compradores, não apenas devido ao aquecimento de seu mercado de consumo - aqui a estratégia New Normal é fundamental - mas também como compradores de ativos, não apenas na Ásia mas no mundo todo.

Como se observou, os Investimentos Diretos Chineses expandiram-se fortemente desde 2010, quase alcançando o patamar dos IDEs americanos no mundo. A compra de ativos, empresas, direitos de exploração, tecnologia, imóveis, marcas, tem dominado a estratégia chinesa de expansão. Além disso projetos de infraestrutura como o One Belt one Road, podem significar um aporte financeiro muito importante para a recuperação global.

Nesse sentido, do ponto de vista da gestão das reservas chinesas houve uma maior diversificação, seja pela expansão do IDE, seja pela diminuição da participação da China como detentora dos títulos do Tesouro dos Estados Unidos.

É fundamental considerar que toda a expansão chinesa é realizada a partir da continuidade da força do dólar como moeda mundial e isso mantem-se se forma sólida mesmo 
depois da crise. No entanto os projetos de expansão do Renminbi, a moeda chinesa, continuam a todo vapor, com a abertura de mercados off shore em Hong Kong e em Londres; a criação de mecanismo de expansão do Renminbi via empréstimos externos; e ainda mecanismos como os swaps cambiais para transações comerciais. Isso reflete também a preocupação chinesa em expandir-se globalmente por meio da difusão de sua moeda, ainda que a passos lentos.

As relações entre Estados Unidos e China mantem-se fortes e simbióticas, principalmente do ponto de vista comercial, com a balança comercial mantendo-se deficitária para os EUA e a China exportando produtos cada vez mais industrializados para os Estados Unidos.

O cenário, no entanto, parece menos complementar quando se analisa os problemas distributivos americanos e a dificuldade do país em expandir a renda interna de sua população. Nesse cenário, o governo Trump mantem altos investimentos em defesa e presença militar, o que pode sinalizar possíveis conflitos com a China.

Do lado chinês o ciclo de crescimento baseado em expansão do consumo interno aliado a maior projeção para fora podem sinalizar maior autonomia frente a dependência com relação ao mercado americano.

O caráter desta expansão chinesa assume cada vez mais contornos de um processo que busca favorecer apenas a própria China, principalmente pela agressividade dos investimentos chineses em todo o mundo, por meio da compra de ativos estratégicos fundamentais para a soberania de países periféricos, como no Brasil.

A ascensão da China e sua projeção global insere nesse sentido novas determinações do imperialismo e, principalmente, instaura um ambiente de forte competitividade global, cujas características e manifestações ainda estão por vir, mas que sem dúvida colocarão enormes dificuldades para as economias periféricas como a brasileira.

\section{Referências}

UNCTAD. "Trade and Development Report 2017: Beyond Austerity: towards a global new deal" (2017). Disponível em: http://unctad.org/en/PublicationsLibrary/tdr2017_en.pdf MILANOVIC, BRANKO. Global inequality - A New Approach for

the Age of Globalization. Harvard University Press (2016). LO, Dic. Developing or Under-developing? Implications of China's 'Going out' for Late Development. SOAS Department of Economics Working Paper No. 198, London, 2016. Disponível em: https://www.soas.ac.uk/economics/research/workingpapers/file113670.pdf 
. China Confronts the Great Recession: 'Rebalancing' Neoliberalism, or Else? In:

Emerging Economies During and After the Great Recession. Editors: Arestis, Philip, Sawyer, M. Palgrave Macmillan UK, 2016.

GOLDSHTEIN, Diana; LUND, Susan; Eckart Windhagen, James Manyika, Philipp Härle, Jonathan Woetzel, The new dynamics of financial globalization. McKinsey Global Institute, 2017.

MARX, Karl. O Capital. Livro 3. Abril Cultural, 1984.

PANITCH, Leo; GINDIN, Sam. The Making of Global Capitalism: The Political Economy of American Empire. Verso, 2013.

IKENBERRY, John G. The Plot Against American Foreign PolicyCan the Liberal Order Survive? Foreign Affairs, 2017.

DUMÉNIL, Gérard e LÉVY, Dominique E. A crise do neoliberalismo. Boitempo Editorial, São Paulo, 2014.

TAVARES, Maria da Conceição. "A retomada da hegemonia norte-americana", Revista de Economia Política, Vol. 5, No. 2, abril/junho. São Paulo: Ed. Brasiliense, 1985.

TAVARES, M. da Conceição \& BELLUZZO, L. G. M. "A mundialização do capital e a expansão do poder americano", in: FIORI, J.L. (Org.) O poder americano. Petrópolis: Editora Vozes, p. 111-138, 2004.

BRAGA, José Carlos Souza \& CINTRA, Marcos Antonio Macedo (2004) "Finanças dolarizadas e capital financeiro: exasperação sob comando americano", in: FIORI, J.L. (Org.) O poder americano. Petrópolis: Editora Vozes.

FERGUSON, Niall. (2007). Not two countries, but one: Chimerica. Em: http://www.telegraph.co.uk/comment/personal-view/3638174/Not-two-countries-but-one-

Chimerica.html

FERGUSON, Niall. \& Moritz Schularick. (2009). The End of Chimerica. WORKING PAPER SUMMARIES.

CINTRA, Marcos A.; PINTO, Eduardo C.; FILHO, Edison B. da Silva. (2015) (Organizadores). "China em transformação : dimensões econômicas e geopolíticas do desenvolvimento / Marcos Antonio Macedo Cintra, Edison Benedito da Silva Filho, Eduardo Costa Pinto (Organizadores) - Rio de Janeiro : Ipea, 2015.

OCAMPO, José A.; ERTEN, Bilge. (2013). "The Global Implications of Falling Commodity Prices". Disponível em http://www.project-syndicate.org/commentary/china-s-growthslowdown-and-the-end-of-the-commodity-price-super-cyle-by-jose-antonio-ocampo-andbilge-erten\#iRdPGvyaBZhv1xRW.99

CALLINICOS, Alex. (2005). Imperialism and global political economy. International Socialism Journal. Issue 108.

$\overline{\text { jan/jun } 2015 .}$

(2014). As múltiplas crises do imperialismo. Marx e o Marxismo v.3, n.4,

. (2009). IMPERIALISM AND GLOBAL POLITICAL ECONOMY

PINTO, Eduardo Costa. O eixo sino-americano e as transformações do sistema mundial: tensões e complementaridades comerciais, produtivas e financeiras. IPEA, 2010.

MEDEIROS, Carlos Aguiar de. Padrões de investimento, mudança institucional e transformação estrutural na economia chinesa. Em: Padrões de desenvolvimento econômico (1950-2008): América Latina, Ásia e Rússia. - Brasília: Centro de Gestão e Estudos Estratégicos, 2013.

MORAIS, Isabela Nogueira de. Desigualdades e políticas públicas na china: investimentos, salários e riqueza na era da sociedade harmoniosa. Ipea, 2015.

WorldBank Database, 2017, 2018 
OECD.

National Bureau Statistics of China.

UNComtrade.

Recebido em 15 de janeiro de 2018. Aprovado em 02 de fevereiro de 2018. 